\title{
MANAGEMENT OF AN INTER-FIRM NETWORK
}




\section{Japanese Management and International Studies}

(ISSN: 2010-4448)

Editor-in-Chief: Yasuhiro Monden (Tsukuba University, Japan)

Published

Vol. 1 Value-Based Management of the Rising Sun edited by Yasuhiro Monden, Kanji Miyamoto, Kazuki Hamada, Gunyung Lee \& Takayuki Asada

Vol. 2 Japanese Management Accounting Today edited by Yasuhiro Monden, Masanobu Kosuga, Yoshiyuki Nagasaka, Shufuku Hiraoka \& Noriko Hoshi

Vol. 3 Japanese Project Management:

KPM - Innovation, Development and Improvement edited by Shigenobu Ohara \& Takayuki Asada

Vol. 4 International Management Accounting in Japan: Current Status of Electronics Companies edited by Kanji Miyamoto

Vol. 5 Business Process Management of Japanese and Korean Companies edited by Gunyung Lee, Masanobu Kosuga, Yoshiyuki Nagasaka \& Byungkyu Sohn

Vol. 6 M\&A for Value Creation in Japan edited by Yasuyoshi Kurokawa

Vol. 7 Business Group Management in Japan edited by Kazuki Hamada

Vol. 8 Management of an Inter-Firm Network edited by Yasuhiro Monden 
Japanese Management and International Studies - Vol. 8

\title{
MANAGEMENT OF AN INTER-FIRM NETWORK
}

\author{
editor

\section{Yasuhiro Monden}

Tsukuba University, Japan 


\section{Published by}

World Scientific Publishing Co. Pte. Ltd.

5 Toh Tuck Link, Singapore 596224

USA office: 27 Warren Street, Suite 401-402, Hackensack, NJ 07601

UK office: 57 Shelton Street, Covent Garden, London WC2H 9HE

\section{Library of Congress Cataloging-in-Publication Data}

Management of an inter-firm network / edited by Yasuhiro Monden.

p. cm. -- (Japanese management and international studies, ISSN 2010-4448 ; vol. 8)

ISBN-13: 978-9814324618

ISBN-10: 9814324612

1. Business networks--Japan. 2. Business networks--Management--Japan.

I. Monden, Yasuhiro, 1940-

HD69.S8M3264 2012

658'.046--dc23

\section{6}

\section{British Library Cataloguing-in-Publication Data}

A catalogue record for this book is available from the British Library.

Copyright $@ 2012$ by World Scientific Publishing Co. Pte. Ltd.

All rights reserved. This book, or parts thereof, may not be reproduced in any form or by any means, electronic or mechanical, including photocopying, recording or any information storage and retrieval system now known or to be invented, without written permission from the Publisher.

For photocopying of material in this volume, please pay a copying fee through the Copyright Clearance Center, Inc., 222 Rosewood Drive, Danvers, MA 01923, USA. In this case permission to photocopy is not required from the publisher.

Typeset by Stallion Press

Email: enquiries@ stallionpress.com

Printed in Singapore. 


\title{
Japan Society of Organization and Accounting (JSOA)
}

\author{
President \\ Kazuki Hamada, Kwansei Gakuin University, Japan \\ Vice Presidents \\ Gunyung Lee, Niigata University, Japan \\ Kanji Miyamoto, Osaka Gakuin University, Japan
}

Directors

Henry Aigbedo, Oakland University, USA

Shufuku Hiraoka, Soka University, Japan

Mahfuzul Hoque, University of Dhaka, Bangladesh

Noriko Hoshi, Hakuoh University, Japan

Tomonori Inooka, Kokushikan University, Japan

Chao Hsiung Lee, National Chung Hsing University, Taiwan

Yoshiyuki Nagasaka, Konan University, Japan

Founder \& Editor-in-Chief

Japanese Management and International Studies

Yasuhiro Monden, Tsukuba University, Japan

\section{Mission of JSOA and Editorial Information}

For the purpose of making a contribution to the business and academic communities, the Japan Society of Organization and Accounting (JSOA), a reformed and expanded organization from the Monden Institute of Management, is committed to publishing the book series, entitled Japanese Management and International Studies, with a refereed system.

Focusing on Japan and Japan-related issues, the series is designed to inform the world about research outcomes of the new "Japanese-style management system" developed in Japan. It includes the Japanese version of management systems developed abroad. In addition, it publishes research by foreign scholars and concerning foreign systems that constitute significant points of comparison with the Japanese system. 
Research topics included in this series are management of organizations in a broad sense (including the business group) and the accounting that supports the organization. More specifically, topics include business strategy, organizational restructuring, corporate finance, M\&A, environmental management, business models, operations management, managerial accounting, financial accounting for organizational restructuring, manager performance evaluation, remuneration systems, and management of revenues and costs. The research approach is interdisciplinary, which includes case studies, theoretical studies, normative studies and empirical studies, but emphasizes real world business.

Each volume contains the series title and a book title which reflects the volume's special theme.

Our JSOA's board of directors has established an editorial board of international standing. In each volume, guest editors who are experts on the volume's special theme serve as the volume editors. 


\title{
Editorial Board
}

\author{
Japanese Management and International Studies
}

Editor-in-Chief

Yasuhiro Monden, Tsukuba University, Japan

Managing Editors

Henry Aigbedo, Oakland University, USA

Kazuki Hamada, Kwansei Gakuin University, Japan

Shufuku Hiraoka, Soka University, Japan

Mahfuzul Hoque, University of Dhaka, Bangladesh

Noriko Hoshi, Hakuoh University, Japan

Tomonori Inooka, Kokushikan University, Japan

Chao Hsiung Lee, National Chung Hsing University, Taiwan

Gunyung Lee, Niigata University, Japan

Yoshiyuki Nagasaka, Konan University, Japan

Editorial Advisory Board

Mohammad Aghdassi, Tarbiat Modarres University, Iran

Mahmuda Akter, University of Dhaka, Bangladesh

Takayuki Asada, Osaka University, Japan

Takahiro Fujimoto, University of Tokyo, Japan

Péter Horváth, University Stuttgart, Germany

Arnd Huchzermeier, WHU Koblenz, Germany

Christer Karlsson, Copenhagen Business School, Denmark

Masanobu Kosuga, Kwansei Gakuin University, Japan

Bruce Henry Lambert, Stockholm School of Entrepreneurship, Sweden

Rolf G Larsson, Lund University, Sweden

John Y. Lee, Pace University, USA

Jose Antonio Dominguez Machuca, University of Sevilla, Spain

Kenneth A. Merchant, University of Southern California, USA

Yoshiteru Minagawa, Nagoya Gakuin University, Japan

Kanji Miyamoto, Osaka Gakuin University, Japan 
Tengku Akbar Tengku Abdullah, Universiti Kebangsaan Malaysia, Malaysia

Jimmy Y.T. Tsay, National Taiwan University, Taiwan

Susumu Ueno, Konan University, Japan

Eri Yokota, Keio University, Japan

Walid Zaramdini, Al Akhawayn University, Morocco 


\section{Contents}

Preface xiii

List of Contributors $\quad$ xvii

Part 1: Strategy for Forming an Inter-Firm Network

1. From Adam Smith's Division of Labor to Network Organization: From the Market Price Mechanism to the Incentive Price Mechanism

Yasuhiro Monden

2. South Korean "Zaibatsu": An Analysis

of Its Historical and Financial Characteristics

Tadashi Hasegawa

Part 2: Management Control of an Inter-Firm Network

3. The Importance of Inter-Company SCM in Consolidated Group Companies and Management Accounting

Kazuki Hamada

4. Profit Allocation Rules to Motivate Inter-Firm

Network Partners to Reduce Overall Costs

Yoshiteru Minagawa

5. The Role of Intangible Assets in Allocating the Inter-Firm Profit of a Global Consolidated Business: International Transfer Pricing

Yasuhiro Monden 
6. Exploratory Research in Cooperative Action for SMEs: The Possibilities of Applying Qualitative Comparative Analysis

Satoshi Arimoto

7. Performance Measurement of an Inter-Firm Network from the Viewpoint of Reduction of Total Lead Time for Investment Recovery Shino Hiiragi

8. The Relationships between a Manufacturing Firm and a Customer Firm: The Situation in Japan 123 Junya Sakaguchi

Part 3: Task Control of Production, Sales and Physical Distribution in an Inter-firm Network

9. Green Economies and Green Processes, and Their Implications for Supply Chains Henry Aigbedo

10. Issue of SCM for Japanese Companies and Their Efforts Toward Green Logistics Yoshiyuki Nagasaka

11. Inter-firm Business Process Management of Companies Specializing in Element Technology: Analysis of a Horizontal Division Network Created by a Cluster of Small Enterprises in Japan

Naoya Yamaguchi

12. Organizational Capability of Master Data Management for Inter-Firm Integration 
13. Deployment of Material Flow Cost Accounting in an Inter-Firm Network

Tomonori Inooka

14. Coordinating Supply Chains by Controlling

Capacity Usage Rate in the Japanese

Car Industry

Fumiko Kurokawa

15. Human Capital Strategy of an Inter-Firm

Network: Contribution to the Evolution of the Management Accounting System, and Examples Thereof

Noriyuki Imai

Index 
This page intentionally left blank 


\section{Preface}

Adam Smith (1776) first advocated that supply and demand in the market would be balanced through the market principle (or market price or supplydemand equilibrium price) of the "invisible hand". This is based on the "division of labor" in the market. However, the market cannot necessarily work well especially in the age of depression.

Thus this volume attempts to propose the system that induces cooperation among the inter-firm network, which is a kind of organization against the concept of "division of labor" in the market. We are going to explore how to design such a network and balance the supply and demand, and finally create mutual satisfaction of all participating firms within the network. This mechanism is mainly based on the "incentive price" system, which will take the place of "market price". As such, proposing the antithesis to Adam Smith's initiated market principle is the main theme of this volume. This new viewpoint and mechanism will develop the new world and can help recover the depressed economy when introduced together with the market competition among the various networks in the industries.

From the above standpoint, the book is into subdivided into three parts, in accordance with the framework of the management theory propounded by Robert Anthony.

\section{PART 1: Strategy for Forming an Inter-Firm Network}

Since a network organization is a "network of various companies", the presence of a core company that plays the role of headquarters is essential. The strategic roles played by the core company of a network organization are two-fold: Recognition of the functions (roles) to be shared among the companies participating in the network and the selection of the member companies. This involves the strategic decision No. 1. The strategic decision No. 2 that the core company should undertake is to determine the forms of business combination of inter-firm relations. 


\section{PART 2: Management Control of an Inter-Firm Network}

One more role of the core company is to encourage candidate member companies to do a good job in the network. In order to make the performance of the network as a whole attractive, the core company should have some incentive systems that motivate the member companies to perform well. Thus the "plan-do-check-action" cycle is conducted by the core company, in which the performance evaluation system for the member companies is crucially important. This role is the "management control" functions of the core company. For this purpose various managerial accounting information of the consolidated business group (network) are needed.

As stated earlier, Adam Smith (1776) first advocated that supply and demand in the market would be balanced through the market principle (or market price) of the "invisible hand". However, the market cannot necessarily work well especially in the age of depression. This volume proposes the management control system that induces cooperation among the interfirm network, especially the joint-profit allocation system as an incentive system of management control.

In this respect, we will also discuss the management of the horizontally allied networks of small and medium companies, as well as the vertically allied networks.

\section{PART 3: Task Control of Production, Sales and Physical Distribution in an Inter-Firm Network}

A network usually consists of member companies from the upstream to the downstream levels of a supply chain, and the core company determines the quantitative allocation of goods in supply and demand among the member companies. In response to the fluctuations in demand in the market, the adjustment of supply of the resources relevant to the supply chain should be made quickly throughout the chain under the direct quantitative control of the core company. This role is called "task control or operational control".

The goals of such operational control include the whole business process efficiency for reducing the lead times in product development, manufacturing and sales processes. The Japanese automobile industry is unique in smoothing the parts usage each hour. The special technique is introduced. It also aims at the logistics efficiency, which includes not only the forward-flowing logistics but also the reverse (green) flowing logistics. 
Further utilization of the master data management for integration of an inter-firm as a whole will be explored.

\section{Acknowledgements}

I am very grateful to Ms. Juliet Lee Ley Chin, the senior commissioning editor of the Social Sciences in the World Scientific Publishing Company for her invaluable advice to make this volume a reality. The contributing authors of this volume are also amply rewarded when their new ideas or knowledge contribute to the literature on business management and managerial accounting, thereby being of some use to people around the world.

Yasuhiro Monden

March 7, 2011 
This page intentionally left blank 


\section{List of Contributors}

\section{Mohammad Aghdassi}

Associate Professor, School of Engineering

Tarbiat Modares University, Iran

P.O. Box 1455-4834, Iran

Tel: +021-801-1001 ext.3396

Fax: +021-800-5040

aghdasim@modares.ac.ir

\section{Henry Aigbedo}

Associate Professor of Operations Management

School of Business Administration, Oakland University, USA

Rochester, MI 48309-4401, USA

Ph.D. in Management Science and Engineering from

Tsukuba University, Japan

Tel: 248-370-4959; Fax: 248-370-4275

haigbedo@oakland.edu

\section{Satoshi Arimoto}

Assistant Professor, Faculty of Economics, Niigata University

M.A. in Commerce from Waseda University

8050 Ikarashi 2-no-cho, Nishi-ku, Niigata, 950-2181, Japan

Tel/Fax: 025-262-6560

s.arimoto@econ.niigata-u.ac.jp

\section{Kazuki Hamada}

Professor, Institute of Business and Accounting,

Kwansei Gakuin University

1-1-155, Uegahara, Nishinomiya, Hyogo, Japan, 662-8501

$\mathrm{Ph}$. D. in Management Science and Engineering from

Tsukuba University

k-hamada@kwansei.ac.jp 


\section{Tadashi Hasegawa}

Professor, School of Management, Kyoto Gakuen University

1 Sogabecho-nanjo-ohtani, Kameoka-City

Kyoto-Prefecture, 621-8555, Japan

MBA from Osaka Prefecture University

Tel: 0771-29-2330

hasegawa@kyotogakuen.ac.jp

\section{Shino Hiiragi}

Project Research Associate

Manufacturing Management Research Center,

Graduate School of Economics, The University of Tokyo

7-3-1 Hongo, Bunkyo-ku, Tokyo, 113-0033, Japan

Doctor of Business Administration and Computer Science from

Aichi Institute of Technology

s_hiiragi@nifty.com

\section{Noriyuki Imai}

Vice President, Toyota Financial Services Corporation

6-1 Ushijima-cho, Nishi-ku, Nagoya, 451-6015, Japan

Ph.D. from Meijo University

silverstone@mta.biglobe.ne.jp

\section{Tomonori Inooka}

Associate Professor

Faculty of Business, Kokushikan University

4-28-1, Setagaya, Setagaya-ku, Tokyo, 154-8515, Japan

M.Eng. from Tokyo University of Science

inooka@kokushikan.ac.jp

\section{Fumiko Kurokawa}

Professor, Dokkyo University,

1-1, Gakuen-cho, Soka-shi, Saitama, 340-0042, Japan

Ph.D. in Management from Meiji University

fkurokaw@dokkyo.ac.jp 


\section{Yoshiteru Minagawa}

Professor, Faculty of Commerce, Nagoya Gakuin University

1-25 Atsuta Nishimachi, Atsuta, Nagoya, 456-8612, Japan

Doctor of Economics from Nagoya University

minagawa@ngu.ac.jp

\section{Yasuhiro Monden}

Professor Emeritus of Tsukuba University

Visiting Professor of NUCB, Global MBA

yasuhirom@mail2.accsnet.ne.jp

\section{Farzad Movahedi Sobhani}

Academic staff of the Science \&

Research Branch of Islamic Azad University, Iran

P.O. Box 1455-4834, Iran

Tel: +021-801-1001 ext.3396

Fax: +021-800-5040

\section{Yoshiyuki Nagasaka}

Professor, School of Management, Konan University

8-9-1 Okamoto, Higasinada, Kobe, 658-8501, Japan

Doctor of Engineering from Osaka University

Tel: +81-78-435-2454; Fax: +81-78-435-2543

nagasaka@konan-u.ac.jp

\section{Junya Sakaguchi}

Associate Professor, School of Accountancy, Kansai University

3-3-35 Yamate-cho, Suita, Osaka, 564-8680, Japan

Tel: 06-6368-1121

Doctor of Business Administration from Kobe University

\section{Naoya Yamaguchi}

Associate Professor, Graduate School of Modern Society and Culture Faculty of Economics, Niigata University

8050 Ikarashi 2-no-cho, Nishi-ku, Niigata, 950-2181, Japan

Tel/Fax: +81-25-262-6504

naoya@econ.niigata-u.ac.jp 